\title{
Modulating the Precursor and Terpene Synthase Supply for the Whole-Cell Biocatalytic Production of the Sesquiterpene (+)-Zizaene in a Pathway Engineered E. coli
}

\author{
Francisco Aguilar ${ }^{\mathbb{D}}$, Thomas Scheper and Sascha Beutel * \\ Institute of Technical Chemistry, Leibniz University of Hannover, Callinstr. 5, 30167 Hannover, Germany; \\ aguilar@iftc.uni-hannover.de (F.A.); scheper@iftc.uni-hannover.de (T.S.) \\ * Correspondence: beutel@iftc.uni-hannover.de; Tel.: +49-511-762-2867; Fax: +49-511-762-3004
}

Received: 19 May 2019; Accepted: 20 June 2019; Published: 24 June 2019

check for updates

\begin{abstract}
The vetiver essential oil from Chrysopogon zizanioides contains fragrant sesquiterpenes used widely in the formulation of nearly $20 \%$ of men's cosmetics. The growing demand and issues in the supply have raised interest in the microbial production of the sesquiterpene khusimol, the main compound of the vetiver essential oil due to its woody smell. In this study, we engineered the biosynthetic pathway for the production of (+)-zizaene, the immediate precursor of khusimol. A systematic approach of metabolic engineering in Escherichia coli was applied to modulate the critical bottlenecks of the metabolic flux towards (+)-zizaene. Initially, production of (+)-zizaene was possible with the endogenous methylerythritol phosphate pathway and the codon-optimized zizaene synthase (ZS). Raising the precursor E,E-farnesyl diphosphate supply through the mevalonate pathway improved the (+)-zizaene titers 2.7-fold, although a limitation of the ZS supply was observed. To increase the ZS supply, distinct promoters were tested for the expression of the ZS gene, which augmented 7.2-fold in the (+)-zizaene titers. Final metabolic enhancement for the ZS supply by using a multi-plasmid strain harboring multiple copies of the ZS gene improved the (+)-zizaene titers 1.3-fold. The optimization of the fermentation conditions increased the (+)-zizaene titers 2.2-fold, achieving the highest (+)-zizaene titer of $25.09 \mathrm{mg} \mathrm{L}^{-1}$. This study provides an alternative strategy to enhance the terpene synthase supply for the engineering of isoprenoids. Moreover, it demonstrates the development of a novel microbial platform for the sustainable production of fragrant molecules for the cosmetic industry.
\end{abstract}

Keywords: khusimene; (+)-zizaene; vetiver essential oil; khusimol; sesquiterpenes; microbial production; metabolic engineering

\section{Introduction}

The cosmetic industry has extensively used essential oils for the formulation of perfumes due to their complex mixture of fragrant hydrocarbons such as ketones, ethers, esters, alcohols, aldehydes, and terpenoids [1]. From these natural products, terpenes such as volatile monoterpenes, sesquiterpenes, and diterpenes are the main constituents, which confer the specific odor to each essential oil [2].

Among the distinct essential oils, the vetiver essential oil (VEO) from the Ch. zizanioides grass has drawn growing attention, because it is used in nearly $20 \%$ of men's luxury perfumes [3]. Characterized by its dark woody smell, VEO holds a world production of 300-350 tons per year [4] with prices ranging from \$380-\$500 per $\mathrm{kg}$ in 2018 [5] and expected growth in the market of \$169.5 million for 2022 [6]. Industrial production of VEO is performed traditionally by steam distillation from vetiver roots, harvested after 12-18 months of growth and at 1-2 m length; usually, this process attains 
an extraction yield of $0.2-3 \%$ and can be improved to $4 \%$ through supercritical fluid extraction $[3,7]$. The recurrent shortages in the supply of VEO from the main producer, Haiti due to rainfalls and earthquakes [3,5], and the increasing market demand has raised the interest towards a reliable biotechnological production of the main constituent of VEO, the sesquiterpene khusimol, which grants the distinctive woody smell.

Similar to most plant sesquiterpenes, the biosynthesis of khusimol initiates from the glycolysis cycle, which generates the precursors' glyceraldehyde 3-phosphate (GAP) and pyruvate for the plastidial methylerythritol phosphate (MEP) pathway, and acetyl coenzyme A (Acetyl-CoA) for the cytoplasmic mevalonate (MEV) pathway [8]. Both pathways converge and catalyze the formation of the terpene precursors isopentenyl pyrophosphate (IPP) and isomer dimethylallyl pyrophosphate (DMAPP), which are further assembled by the farnesyl diphosphate synthase (IspA) to form the universal sesquiterpene substrate E,E-farnesyl diphosphate (FDP) [9]. In the (+)-zizaene (syn. khusimene) pathway, FDP is cyclized by the zizaene synthase (ZS) to yield (+)-zizaene and further hydroxylated to khusimol by a specific P450 cytochrome monooxygenase [10].

The biosynthetic pathway of khusimol should be possible in E. coli because of the positive results for the in vivo production of many sesquiterpenes [11]. Contrary to plants, E. coli produces endogenous FDP exclusively by the MEP pathway and is vital for the biosynthesis of the intermediates undecaprenyl diphosphate (UDP) and octaprenyl diphosphate (ODP) [12]. Accordingly, UDP is the direct precursor of peptidoglycans, used for cell wall formation [13], and ODP is involved in the respiratory chain for the biosynthesis of distinct quinones [14]. Consequently, amounts of FDP in E. coli are limited; thus, efforts have been made to engineer the MEP pathway to enhance the supply of FDP. As an example, the overexpression of the MEP pathway genes 1-Deoxy-D-xylulose 5-phosphate synthase (DXS) and 1-deoxy-D-xylulose 5-phosphate reductoisomerase (DXR) increased the FDP levels and improved the amounts of lycopene up to $22 \mathrm{mg} \mathrm{L}^{-1}$ [15]. Similarly, overexpression of the DXS synthase and additionally, the isoprenyl diphosphate isomerase (Idi) with the farnesyl pyrophosphate synthase (FPS) reached valerenadiene titers of $2.09 \mathrm{mg} \mathrm{L}^{-1}$ [12]. Although overexpression of the MEP pathway improved the precursor supply, the terpene titers did not reach industrial levels, possibly due to control mechanisms of E. coli or the formation of intermediates that limited the precursor supply [16,17].

As an alternative to raise the FDP supply, the heterologous MEV pathway was engineered in E. coli by Keasling and co-workers for the in vivo production of amorpha-4,11-diene [17]. The heterologous pathway involved the cloning of eight genes from E. coli and Saccharomyces cerevisiae into two operons: MevT operon converted acetyl-CoA to mevalonate and MBIS operon catalyzed mevalonate to IPP and DMAPP that led to FDP, yielding $112.2 \mathrm{mg} \mathrm{L}^{-1}$ as the highest amorpha-4,11-diene titer. The microbial platform was further enhanced for the production of bisabolene by optimizing the codon usage to E. coli for the $S$. cerevisiae genes and assembling the eight genes into one single operon under the control of the lacUV5 (MevT genes) and trc promoter (MBIS genes) [18]. As a result, the upgraded platform boosted the FDP supply and achieved titers of $900 \mathrm{mg} \mathrm{L}^{-1}$ of bisabolene.

The previously mentioned studies augmented the supply of the substrate FDP, which is further catalyzed in the terpene pathway by a terpene synthase (TPS), performing complex reactions that yield sesquiterpenes with precise structure and stereochemistry [19]. In the biosynthesis of khusimol, the TPS is the ZS that catalyzes the cyclization of FDP to the tricyclic (+)-zizaene. Its enzymatic characterization has been described by a recombinant codon-optimized variant fused to the small ubiquitin-related modifier (SUMO), which increased the solubility of ZS and expressed heterologously in E. coli [10]. Moreover, the catalytical specificity and enzymatic kinetics of the ZS enzyme have been further characterized [20].

In this study, we report the metabolic engineering of (+)-zizaene biosynthesis in E. coli strains. The engineering of the biosynthetic pathway involved the overexpression of the MEV pathway to enhance the FDP supply, the evaluation of promoters to efficiently express the ZS, and the engineering of multi-plasmid strains with multiple copies of ZS to boost the ZS supply. Moreover, optimization of 
the fermentation conditions and evaluation of E. coli strains were analyzed to improve the production of (+)-zizaene.

\section{Materials and Methods}

\subsection{Engineering of Vectors and Strains}

The description of vectors and strains is summarized in Table 2. The pETSUMO::ZIZ(co) vector was obtained from our previous study [10], and the sequence of the codon-optimized SUMO-fused ZS gene was described in GenBank accession KP231534. The vector pBbA5c-MevT(CO)-MBIS (CO, ispA), encoding the MEV pathway, was a gift from Jay Keasling \& Taek Soon Lee (Addgene plasmid \#35151). The pJbei-6411 vector for the expression with the arabinose operon was a gift from Taek Soon Lee (Addgene plasmid \#47050).

The cloning procedures were carried out by the NEBuilder HiFi DNA Assembly method, and PCR reactions were performed with the Q5 HiFi DNA polymerase, both following the provider protocols (New England BioLabs, USA). Synthesis of oligonucleotides and sanger sequencing for clone confirmation were performed by Microsynth Seqlab (Germany), and primer sequences are described in Table 1.

Table 1. Primers used in this investigation.

\begin{tabular}{ccc}
\hline Primers & Description & Reference \\
\hline ZS-F-Mev & catccagcgtaataaataagGATCTAGGAGGTAATGGGCAGCAGCCATCATC & This study \\
ZS-R-Mev & gagatccttactcgagtttgTCACACCGGAATCAGATTTACATAC & This study \\
pJ6411-F-ZS & cccaagattacgtacattg & This study \\
pJ6411-R-ZS & ttctttatcctcctagatctttgaattcccaaaaaacg & This study \\
ZS-F-pJ6411 & ccgttttttgggaattcaaagatctaggaggataaagaaATGGGCAGCAGCCATCATC & This study \\
ZS-R-pJ6411 & tcaatgtacgtaatcttgggTCACACCGGAATCAGATTTACATAC & This study \\
\hline
\end{tabular}

Upper case sequences: Inserts. Lower case sequences: backbone vector. Upper case underlined sequences: IRES

For the production of (+)-zizaene by a single polycistronic vector, the ZS gene was cloned into the pMev vector, directly after the IspA gene to yield the pMevZS vector. In brief, the ZS gene was amplified from the pETZS vector by respective primers with complementary overhangs to the BamHI site of the pMev vector. Additionally, an internal ribosome entry site (IRES) (GATCTAGGAGGTA) from the MEV operon was cloned upstream from the ZS gene. Thereafter, the pMev vector was digested with BamHI, assembled with the ZS gene and E. coli NEB 10-beta competent cloning strain (New England BioLabs), which is specific for large vectors, was transformed with the pMev vector. For the testing of the $\mathrm{P}_{\mathrm{BAD}}$ promoter through the pJbeiZS plasmid, the cytochrome P450 operon from pJbei-6411 vector was removed, and the $Z S$ gene from the $\mathrm{pETZS}$ vector was inserted instead. For that, both the insert and backbone were amplified with complementary overhangs by PCR methods, seamlessly assembled, and E. coli TOP10 competent cloning strains (IBA, Germany) were transformed for respective screening.

For the production of (+)-zizaene, E. coli expression strains were transformed or co-transformed with the respective plasmids by common methods [21]. An exception was the BZS+Mev strain, where the E. coli TOP10 competent cloning strain was used because expression with the arabinose operon requires a non-metabolizing arabinose strain [22]. 
Table 2. Strains and plasmids used in this investigation.

\begin{tabular}{|c|c|c|c|}
\hline Plasmid Reference & Plasmid Name & $\begin{array}{l}\text { Description (Origin of Replication, } \\
\text { Promoter, Antibiotic Resistance } \\
\text { and Genes) }\end{array}$ & Reference \\
\hline pETZS & pETSUMO::ZIZ(co) & $\begin{array}{l}\text { pBR322, PT7, Kan, harboring the } \\
\text { codon-optimized SUMO-fused ZS gene } \\
\text { from Ch. zizanioides }\end{array}$ & [10] \\
\hline $\mathrm{pMev}$ & pBbA5c-MevT(CO)-MBIS (CO, ispA) & $\begin{array}{l}\text { p15A, PlacUV5, Cam, harboring the } \\
\text { mevalonate pathway genes: AtoB, HMGS, } \\
\text { tHMGR, MK, PMK, PMD, Idi and IspA*. }\end{array}$ & [18] \\
\hline pJbei-6411 & pJbei-6411 & $\begin{array}{l}\text { pBBR1, } \mathrm{P}_{\mathrm{BAD}}, \text { Kan, harboring the arabinose } \\
\text { operon with the cytochrome P450 } \\
\text { (CYP153A6) from Sphingomonas sp. }\end{array}$ & [23] \\
\hline pMevZS & $\begin{array}{l}\text { pBbA5c-MevT(CO)-MBIS (CO, } \\
\text { ispA)-SUMO::ZIZ(co) }\end{array}$ & $\begin{array}{l}\text { plbA, PlacUV } \mathrm{S}, \mathrm{Cam}, \text { harboring the } \\
\text { mevalonate pathway genes* and the } \\
\text { codon-optimized SUMO-fused ZS gene } \\
\text { from Ch. zizanioides }\end{array}$ & This study \\
\hline pJbeiZS & pJbei-6411-SUMO::ZIZ(co) & $\begin{array}{l}\text { pBBR1, } \mathrm{P}_{\mathrm{BAD}}, \mathrm{Kan} \text {, harboring the arabinose } \\
\text { operon and the codon-optimized } \\
\text { SUMO-fused ZS gene from Ch. zizanioides }\end{array}$ & This study \\
\hline Strains & \multicolumn{2}{|c|}{ Genotype/Description } & Reference \\
\hline E. coli $\mathrm{TOP} 10$ & \multicolumn{2}{|c|}{ 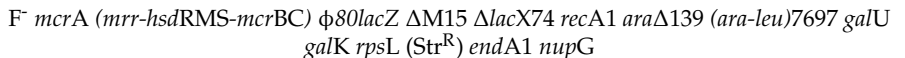 } & IBA \\
\hline E. coli Bl21(DE3) & \multicolumn{2}{|c|}{$\mathrm{F}^{-}$ompT hsdS $S_{B}\left(r_{\mathrm{B}}^{-} m_{\mathrm{B}}^{-}\right)$gal dcm (DE3) } & Novagen \\
\hline E. coli Tuner(DE3) & \multicolumn{2}{|c|}{$\mathrm{F}^{-}$ompT hsdS $S_{B}\left(r_{\mathrm{B}}^{-} m_{\mathrm{B}^{-}}\right)$gal dcm lacY1(DE3) } & Novagen \\
\hline E. coli NEB 10-beta & \multicolumn{2}{|c|}{$\begin{array}{c}\Delta \text { (ara-leu) } 7697 \text { araD139 fhuA } \Delta \text { lacX74 galK16 galE15 e14- } \phi 80 \mathrm{~d} l a c Z \Delta M 15 \text { recA1 relA1 } \\
\text { endA1 nupG rpsL (StrR) rph spoT1 } \Delta \text { (mrr-hsdRMS-mcrBC) }\end{array}$} & NEB \\
\hline E. coli SHuffle T7 & \multicolumn{2}{|c|}{$\begin{array}{c}\left.\text { sulA11 R(mcr-73::miniTn10-Tet }{ }^{\mathrm{S}}\right) 2(\mathrm{dcm}) R\left(z g b-210:: T n 10-\mathrm{Tet}^{\mathrm{S}}\right) \text { endA1 } \Delta g o r \\
\Delta(\text { mcrC-mrr }) 114:: I S 10\end{array}$} & NEB \\
\hline E. coli SHuffle T7 lysY & \multicolumn{2}{|c|}{ 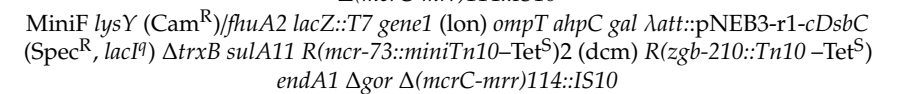 } & NEB \\
\hline Mev & \multicolumn{2}{|c|}{ E. coli $\mathrm{Bl} 21(\mathrm{DE} 3)$ harboring $\mathrm{pMev}$} & This study \\
\hline ZS & \multicolumn{2}{|c|}{ E. coli $\mathrm{Bl} 21(\mathrm{DE} 3)$ harboring pETZS } & This study \\
\hline MevZS & \multicolumn{2}{|c|}{ E. coli $\mathrm{Bl} 21(\mathrm{DE} 3)$ harboring pMevZS } & This study \\
\hline $\mathrm{BZS}+\mathrm{Mev}$ & \multicolumn{2}{|c|}{ E. coli TOP10 harboring pMev and pJbeiZS } & This study \\
\hline TZS+Mev & \multicolumn{2}{|c|}{ E. coli $\mathrm{Bl} 21(\mathrm{DE} 3)$ harboring $\mathrm{pMev}$ and pETZS } & This study \\
\hline TZS+MevZS & \multicolumn{2}{|c|}{ E. coli $\mathrm{Bl} 21(\mathrm{DE} 3)$ harboring pMevZS and pETZS } & This study \\
\hline T-TZS+MevZS & \multicolumn{2}{|c|}{ E. coli Tuner(DE3) harboring pMevZS and pETZS } & This study \\
\hline SH-TZS+MevZS & \multicolumn{2}{|c|}{ E. coli SHuffle T7 harboring pMevZS and pETZS } & This study \\
\hline SHL-TZS+MevZS & \multicolumn{2}{|c|}{ E. coli SHuffle T7 lys $Y$ harboring pMevZS and pETZS } & This study \\
\hline
\end{tabular}

Kan, kanamycin and Cam, chloramphenicol.

\subsection{Evaluation of the Engineered Strains for the Production (+)-zizaene}

Cultivations of $E$. coli were performed by inoculating $100 \mu \mathrm{L}$ of respective strains from glycerol stocks to $10 \mathrm{~mL}$ Lysogeny Broth (LB) pre-culture broths at $37^{\circ} \mathrm{C}$ with respective antibiotics (kanamycin at $30 \mu \mathrm{g} \mathrm{L} \mathrm{L}^{-1}$ and, or chloramphenicol at $34 \mu \mathrm{g} \mathrm{L}^{-1}$ ) until the stationary phase. Furthermore, production cultures in sealed baffled shake-flasks with $35 \mathrm{~mL}$ of defined non-inducing broth (DNB) [24] were inoculated with $2 \%(\mathrm{v} / \mathrm{v})$ of seed culture and grown at $37^{\circ} \mathrm{C}$ on a rotatory shaker $(150 \mathrm{rpm})$. After cultures reached a cell density of $\mathrm{OD}_{600} 0.6,(+)$-zizaene production was induced by adding varying levels $(0.1,0.5$, and $1.0 \mathrm{mM}$ ) of isopropyl- $\beta$-D-1-thiogalactopyranoside (IPTG) and an overlay of $4 \mathrm{~mL}$ iso-octane at $20^{\circ} \mathrm{C},(150 \mathrm{rpm})$ as a two-phase partitioning culture. After $24 \mathrm{~h}$ of induction, samples were taken promptly for analytical measurements that included dried cell weight (DCW), cell density, soluble ZS protein, and (+)-zizaene concentrations.

\subsection{Optimization of the Fermentation Conditions for the Production (+)-zizaene}

Cultivation and analytical procedures for media evaluation, optimization of growth temperature and media $\mathrm{pH}$, and testing of E. coli strains were carried out as described before with the best performing strain. The evaluation of media comprised the defined media: defined non-inducing broth (DNB), M9 minimal medium (M9) [25], and a modified Aparicio defined medium (ADM) with the following composition $\left(\mathrm{g} \mathrm{L}^{-1}\right)$ : $\left(\mathrm{NH}_{4}\right)_{2} \mathrm{SO}_{4} 10.0, \mathrm{NaCl} 1.2, \mathrm{~K}_{2} \mathrm{SO}_{4} 1.1, \mathrm{MgSO}_{4} \cdot 7 \mathrm{H}_{2} \mathrm{O} 0.15, \mathrm{~K}_{2} \mathrm{HPO}_{4}$ 9.3, $\mathrm{KH}_{2} \mathrm{PO}_{4} 2.03, \mathrm{CaCl}_{2} 0.01, \mathrm{FeSO}_{4} \cdot 7 \mathrm{H}_{2} \mathrm{O} 0.001$, and $\mathrm{CuSO}_{4} \cdot 5 \mathrm{H}_{2} \mathrm{O} 0.001$ [26]. Defined media were 
set to $\mathrm{pH} 7.2$ and $5 \mathrm{~g} \mathrm{~L}^{-1}$ of glucose respectively. Additionally, the complex terrific broth (TB) [21] was used as a control. The factorial design for the $\mathrm{pH}$ and temperature optimization consisted of two factors with the following levels: $\mathrm{pH}(6.5,7$, and 7.5$)$ and temperature $\left(16,20,24\right.$, and $\left.28{ }^{\circ} \mathrm{C}\right)$, for a total of 12 combinations with three replicates. Data were analyzed and plotted using the Minitab 16 software (USA).

\subsection{Analytical Measurements}

\subsubsection{ZS Protein Gel Electrophoresis Analysis}

Production culture samples were normalized to an $\mathrm{OD}_{600} 2$, centrifuged for $10 \mathrm{~min}(10,000 \times g$ at $4{ }^{\circ} \mathrm{C}$ ) and free-media pellet was resuspended in $300 \mu \mathrm{L}$ extraction buffer (50 mM MOPS, $150 \mathrm{mM}$ $\mathrm{NaCl}, 5 \mathrm{mM}$ DTT, 10\% (v/v) glycerol, $\mathrm{pH}$ 7.5). Cells were disrupted through an ultrasonicator (Sartorius Labsonic, Goettingen, Germany) and soluble and insoluble protein fractions were separated after 30 min centrifugation $\left(10,000 \times g\right.$ at $\left.4{ }^{\circ} \mathrm{C}\right)$. Protein fraction samples were mixed with $2 \times 1$ loading buffer, heated at $95{ }^{\circ} \mathrm{C}$ for $5 \mathrm{~min}$ and analyzed through a $10 \%$ sodium dodecyl sulfate polyacrylamide gel electrophoresis (SDS-PAGE).

\subsubsection{Identification and Measurement of $(+)$-zizaene by Gas Chromatography Analysis}

Samples of $150 \mu \mathrm{L}$ from the iso-octane overlay from production cultures were transferred to GC-vials for gas chromatography analysis and product identification was carried out through GC-MS using an Agilent 7890B system (Agilent, Santa Clara, CA, USA) with the following settings: sample injections of $0.5 \mu \mathrm{L}$ on-column mode through a $30 \mathrm{~m}$ VF-WAXms capillary column $(0.25 \mathrm{~mm}$ internal diameter I.D. $\times 0.25 \mu \mathrm{m}$, Agilent, USA); oven program of $40^{\circ} \mathrm{C}$ for $3 \mathrm{~min}$, increasing to $230^{\circ} \mathrm{C}\left(10^{\circ} \mathrm{C}\right.$ $\mathrm{min}^{-1}$ ) and final hold of $10 \mathrm{~min}$; helium 5.0 carrier gas at a constant gas flow of $1 \mathrm{~mL} \mathrm{~min}{ }^{-1}$; temperature of $230{ }^{\circ} \mathrm{C}$ for ion source, and $150{ }^{\circ} \mathrm{C}$ for quadrupole; mass scan range of $33-300 \mathrm{~m} / \mathrm{z}$ and ionization energy to $70 \mathrm{eV}$. Terpene products were identified by comparison of retention indices [27] and mass spectra of samples with authentic standards from the VEO and references from the mass spectral NIST 14 database.

Quantification of (+)-zizaene was performed by GC-FID with a GC-2010 plus GC system coupled to a flame ionization detector (Shimadzu, Japan) equipped with a $30 \mathrm{~m}$ Zebron ZB-Wax Plus column (0.25 mm I.D. $\times 0.25 \mu \mathrm{m}$, Phenomenex, USA). Samples of $1 \mu \mathrm{L}$ were injected under a splitless mode with an injector temperature of $240{ }^{\circ} \mathrm{C}$. The initial oven temperature was set to $40^{\circ} \mathrm{C}$ for $20 \mathrm{~s}$, ramped at $10{ }^{\circ} \mathrm{C} \mathrm{min}$ min $^{-1}$ to $200{ }^{\circ} \mathrm{C}$, held for $0.5 \mathrm{~min}$, increased at a rate of $30^{\circ} \mathrm{C} \mathrm{min}^{-1}$ to $230{ }^{\circ} \mathrm{C}$, and held finally for $2 \mathrm{~min}$. Because the (+)-zizaene standard is not commercially available, an $\alpha$-cedrene standard was used as an equivalent standard due to the relative abundance of the main peaks from the mass spectra as described in our previous report [20].

\section{Results}

\subsection{Engineering the Production of (+)-zizaene by the MEP Pathway}

In this study, we engineered the biosynthetic pathway in E. coli for the production of (+)-zizaene, using glucose as the sole carbon source (Figure 1). The key enzyme of the biosynthesis of $(+)$-zizaene is the ZS, which catalyzes the cyclization of the substrate FDP to (+)-zizaene. Due to the plant origin of TPS, most are expressed poorly in E. coli, leading to the formation of insoluble proteins (inclusion bodies) $[28,29]$. To improve TPS solubility, a recombinant ZS variant was used, which was codon-optimized for E. coli and fused with the SUMO moiety from our previous work [30]. 


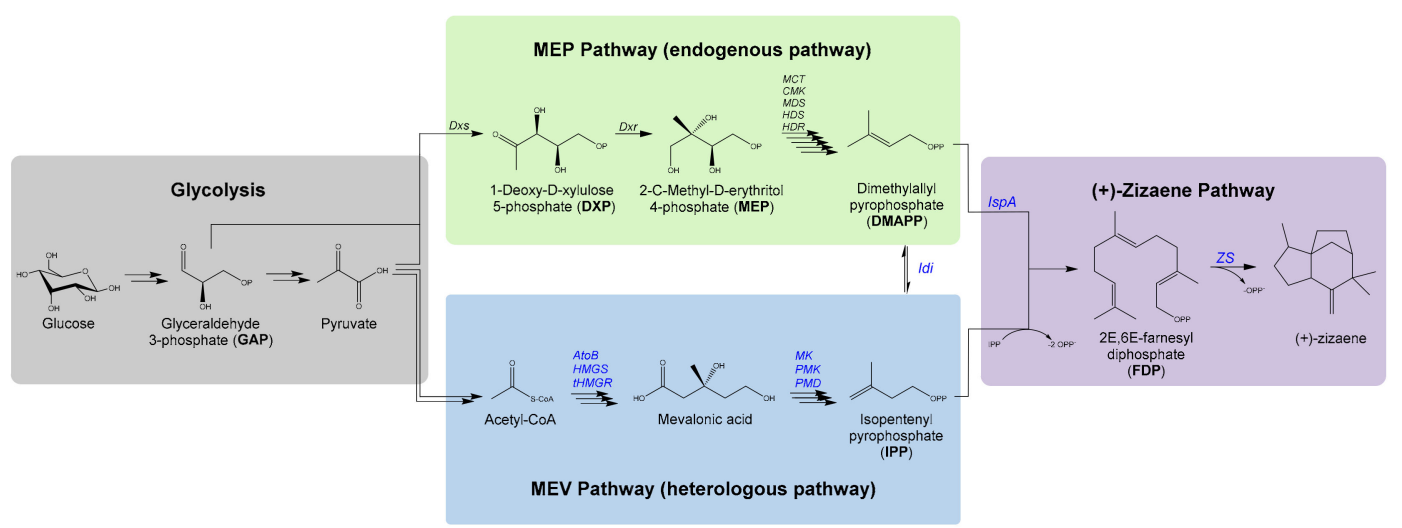

Figure 1. Biosynthetic pathway engineered for the production of (+)-zizaene in E. coli by the expression of the native methylerythritol phosphate (MEP) pathway, the heterologous MEV pathway and the (+)-zizaene pathway. Heterologous expressed enzymes highlighted in blue. The MEP pathway comprise the following enzymes: 1-Deoxy-D-xylulose 5-phosphate synthase (Dxs), 1-deoxy-D-xylulose 5-phosphate reductoisomerase (Dxr), MEP cytidyl transferase $(M C T)$, cytidyl MEP kinase $(C M K)$, MEP-2,4-cyclodiphosphate synthase (MDS), (E)-4-hydroxy-3-methylbut-2-enyl diphosphate synthase (HDS), and (E)-4-hydroxy-3-methylbut-2-enyl diphosphate reductase (HDR). The MEV heterologous pathway consisted of the following enzymes: acetyl-CoA acetyltransferase (AtoB), HMG-CoA synthase (HMGS), truncated HMG-CoA reductase (tHMGR), mevalonate kinase (MK), phosphomevalonate kinase (PMK), mevalonate diphosphate decarboxylase (PMD), and isoprenyl diphosphate isomerase (Idi). The (+)-zizaene pathway comprises the farnesyl diphosphate synthase (IspA) and the zizaene synthase $(Z S)$.

For the overexpression of (+)-zizaene, the production cultures were performed by the two-phase partitioning method [31] with a DNB medium and an overlay of iso-octane, which reduces the loss of (+)-zizaene due to its volatility. After $24 \mathrm{~h}$ of culture, organic phases from production cultures were obtained and analyzed through GC-MS for the identification of terpenes. All tested strains produced $(+)$-zizaene as the main product $(90 \%)$ and $\beta$-acoradiene as a side product $(10 \%)$ (Figure 2$)$, except for the Mev strain (negative control) because it lacks the ZS gene and harbors the MEV pathway (Figure 3a). Additionally, the Mev strain produced farnesol, which is a product from the hydroxylation of FDP by endogenous phosphatases from E. coli [32].

A

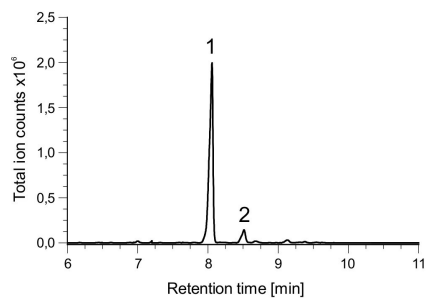

B

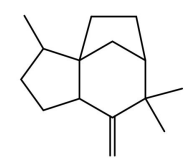

(+)-zizaene (1)

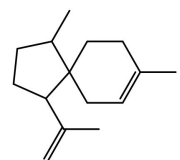

$\beta$-acoradiene (2)
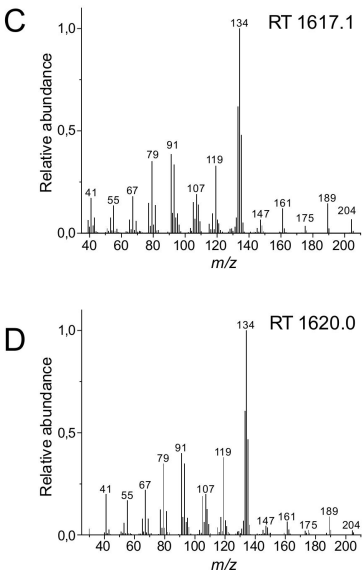

Figure 2. Identification of terpene products by GC-MS. (A) Total ion chromatogram. (B) Chemical structures of the identified products. (C) Mass spectra of (+)-zizaene from the sample of the ZS+MevZS strain. (D) Mass spectra of (+)-zizaene authentic standard from the vetiver essential oil. Comparison of mass spectra for $\beta$-acoradiene is shown in the Supplementary Table S1. 
A

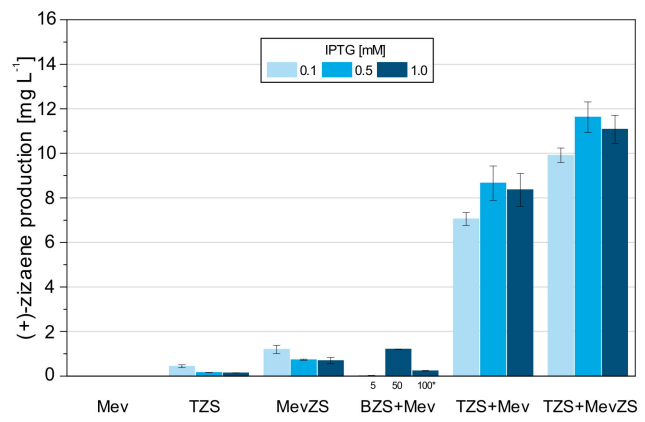

C

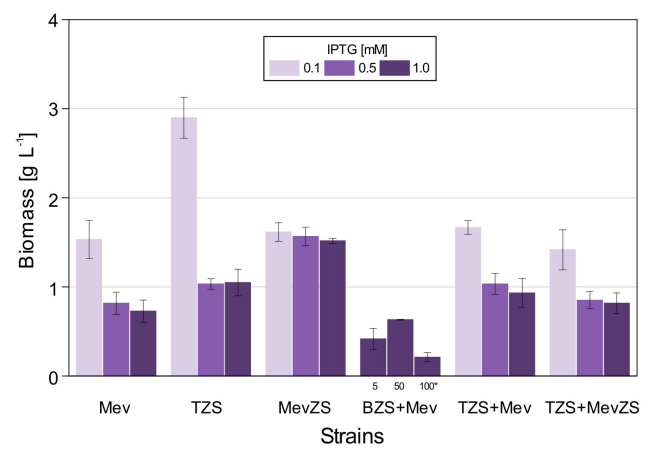

B

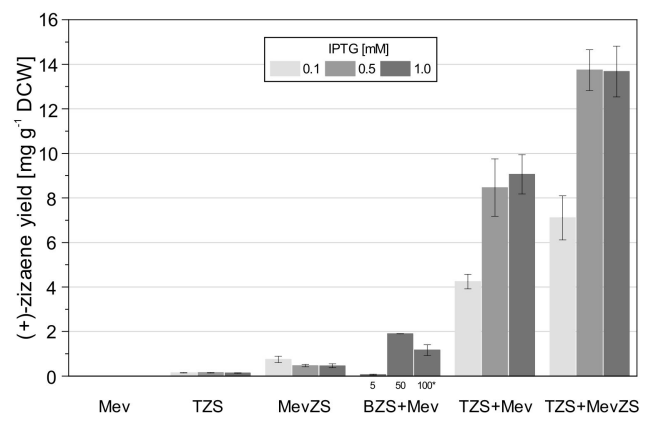

D

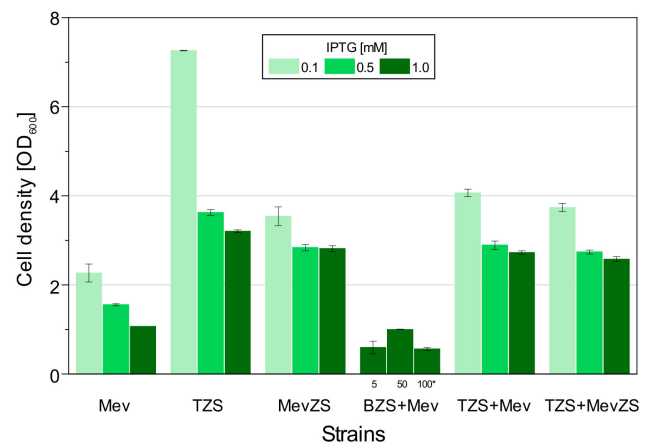

Figure 3. Comparison of the performance of the engineered E. coli BL21(DE3) strains induced at different IPTG levels. (A) (+)-zizaene titers. (B) (+)-zizaene yields. (C) biomass from cell dry weight (D) cell density. Data are the mean of four independent replicates from production cultures after $24 \mathrm{~h}$ of induction with DNB medium, and the error bars represent the standard deviation. * BZS+Mev E. coli Top10 strain induced with $1 \mathrm{mM}$ IPTG and different levels of arabinose (Ara).

As a first attempt to produce (+)-zizaene, the TZS strain was constructed with the ZS gene under the control of the T7 promoter and the FDP supply originated from the endogenous MEP pathway from E. coli BL21(DE3) strain. As shown in Figure 3a, the (+)-zizaene titer of the TZS strain was the lowest when compared to all the tested strains; however, it achieved the highest cell growth (biomass $2.9 \mathrm{~g} \mathrm{~L}^{-1}$ and cell density of $\mathrm{OD}_{600} 7.2$, Figure $3 \mathrm{c}, \mathrm{d}$ ) and amounts of soluble ZS protein (Figure $4 \mathrm{~b}$ ) for the TZS strain induced at $0.1 \mathrm{mM}$ IPTG. These observations suggest a low metabolic burden due to the overexpression of a single recombinant protein (ZS). Moreover, it evidences the limited supply of the endogenous FDP from E. coli, which is required for the biosynthesis of isoprenoid quinones and peptidoglycans $[13,14]$.

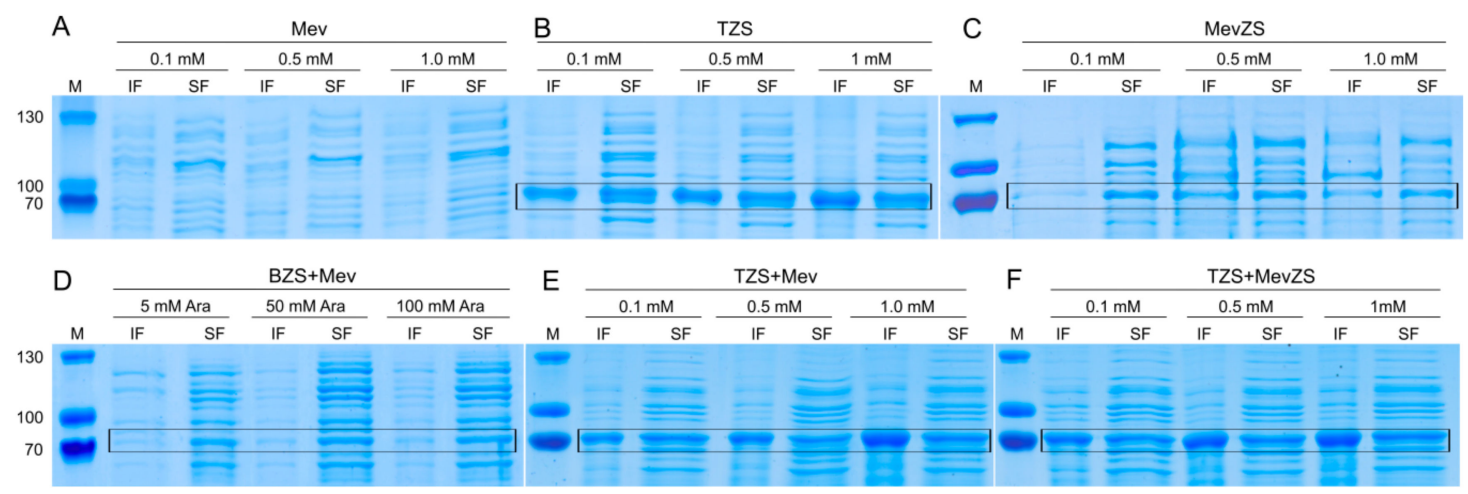

Figure 4. Evaluation of the overexpression of the soluble (SF) and insoluble (IF) ZS protein fractions from the engineered E. coli BL21(DE3) strains, induced at different IPTG levels by 10\% SDS-PAGE. (M) molecular marker. * BZS+Mev induced with $1 \mathrm{mM} \mathrm{IPTG}$ and different levels of arabinose (Ara). 


\subsection{Improving the Titers of (+)-zizaene through the Mevalonate Pathway}

To raise the supply of the precursor FDP, the polycistronic pMevZS vector was constructed with the ZS gene and the exogenous MEV pathway (Figure S1), which was obtained from the pMEV vector that harbors the following genes: AtoB, $H M G S^{*}, \mathrm{tHMGR}{ }^{*}, M K^{*}, P M K^{*}, P M D, I D I$, and IspA (*genes from S. cerevisiae that were codon-optimized to $E$. coli) [18]. Consequently, a single mRNA transcript was expressed under the control of the lacUV5 promoter. As a result, overexpression of the heterologous MEV pathway with the ZS gene (MevZS strain) induced with $0.1 \mathrm{mM} \mathrm{IPTG} \mathrm{augmented} \mathrm{the} \mathrm{(+)-zizaene}$ production and yield by 2.7 and 5-fold respectively when compared to the TZS strain (Figure 3a,b). Thus, a relation was observed in both TZS and MevZS strains, where higher amounts of IPTG increased the overexpression of insoluble ZS protein (Figure $4 a, c)$. Moreover, overexpression of the MEV pathway generated a strong metabolic burden, where cell growth diminished by 1.8-fold biomass and 2.1-fold cell density when compared to that of the strain lacking the MEV pathway (TZS strain) (Figure 3c,d). Although the overexpression of the MEV pathway raised the FDP supply, the production of soluble ZS protein declined dramatically when compared to the TZS strain (Figure 4c), suggesting that the ZS supply became the limiting factor.

\subsection{Effect of Promoters on the Overexpression of the ZS Gene}

The low ZS supply demonstrated by the MevZS strain could result from either expression mechanisms of polycistronic vectors and, or by the promoter strength. To prove these hypotheses, multi-vector strains were constructed harboring the following plasmids: polycistronic $\mathrm{pMev}$ vector (MEV pathway) and monocistronic ZS vector ((+)-zizaene pathway). Two versions of the ZS vectors were constructed in order to test the effect of promoters on the ZS supply. The designed ZS vectors comprised the pETZS vector with the strong T7 promoter and the pJbeiZS vector harboring the weak $\mathrm{P}_{\mathrm{BAD}}$ promoter (Figure S2). The overexpression of the $\mathrm{ZS}$ gene under the control of the $\mathrm{P}_{\mathrm{BAD}}$ promoter (BZS+Mev strain) did not enhance the (+)-zizaene titers when compared to the MevZS strain, but it did increase the (+)-zizaene yield by 2.5 -fold when induced with $50 \mathrm{mM}$ arabinose (Figure 3b). Nevertheless, the BZS+Mev strain showed the lowest cell growth of all the tested strains (biomass $0.63 \mathrm{~g} \mathrm{~L}^{-1}$ and cell density of $\mathrm{OD}_{600} 1.0$, Figure 3c,d). Furthermore, overexpression of the $Z S$ gene controlled by the T7 promoter (TZS+Mev strain) raised the amounts of soluble ZS protein when compared to that of the induced with the $\mathrm{P}_{\mathrm{BAD}}$ promoter (Figure $\left.4 \mathrm{~d}, \mathrm{e}\right)$. As a consequence, the (+)-zizaene production and yield augmented 7.2 and 4.4-fold, respectively when compared to the BZS+Mev strain, and 7.2 and 11.3-fold correspondingly when compared to the MevZS strain (Figure 3a,b). Such strategy improved the ZS supply and consequently restored the flux balance of the (+)-zizaene biosynthesis.

\subsection{Enhancing the ZS Supply by Engineering Multiple Copies of the ZS Gene}

Overexpression of the ZS gene with the T7 promoter seemed to overcome the ZS supply limitations of the MevZS and BZS+Mev strains. Nevertheless, the optimal amount of ZS to catalyze the FDP supply still remains unknown. To increase the ZS supply even further, a multi-vector strain that harbored two copies of the ZS gene was engineered. For that, the TZS+MevZS strain was developed, harboring the pETZS and pMevZS vectors, and controlling the expression of the ZS genes by the T7 and lacUV5 promoters. As a result, the multi-copy ZS gene strain achieved the best results of all the constructed strains (titer: $13.7 \mathrm{mg} \mathrm{L}^{-1}$ and yield $11.6 \mathrm{mg} \mathrm{g}^{-1} \mathrm{DCW}$ ) and raised 1.3-fold the (+)-zizaene titers and 1.6-fold the yields in comparison to the TZS+Mev strain (one ZS gene copy) (Figure 3a,b). Moreover, it augmented the (+)-zizaene production and titer by 9.7 and 18.4-fold correspondingly when compared to the single-vector MevZS strain. These results suggest that the bottleneck of the metabolic flux was still the ZS supply, which could be improved by the combination of the T7 promoter with multiple copies of the ZS gene, harbored on a multi-vector strain. 


\subsection{Optimization of Fermentation Conditions and Evaluation of E. coli Strains}

To raise further the production of (+)-zizaene, fermentation tests were carried out at shake flask scale, comprising the evaluation of culture media, optimization of growth temperature and media $\mathrm{pH}$, and testing of E. coli strains. Accordingly, the mineral-salt defined media DNB, ADM, and M9 were tested due to their previous use in metabolic engineering studies and suitability to control carbon-limited growth required for fed-batch or continuous cultivations to reach high-cell density cultures [33]. To compare the performance of defined media against complex media, the TB broth was used. As a result, substantial differences were observed between the defined media, where the highest (+)-zizaene levels and yields were obtained by ADM media, followed by DNB and M9 media (Figure 5a). Consequently, the ADM medium was 1.8-fold higher than the DNB medium for the (+)-zizaene titers and 1.2-fold higher for the (+)-zizaene yields. Both tested media were of similar formulation with the exception of the trace elements and nitrogen composition, whereas the concentration of nitrogen of the ADM medium was 2.5-fold higher than the DNB medium. Likewise, cell growth followed a similar behavior to that of the (+)-zizaene production among the tested media, where the complex TB broth had the highest cell growth when compared to the defined media tests (Figure 5b). However, the ADM medium obtained the highest (+)-zizaene yields $\left(16.2 \mathrm{mg} \mathrm{g} \mathrm{DCW}^{-1}\right)$ when compared to all the tests and was consequently selected for further tests.

A

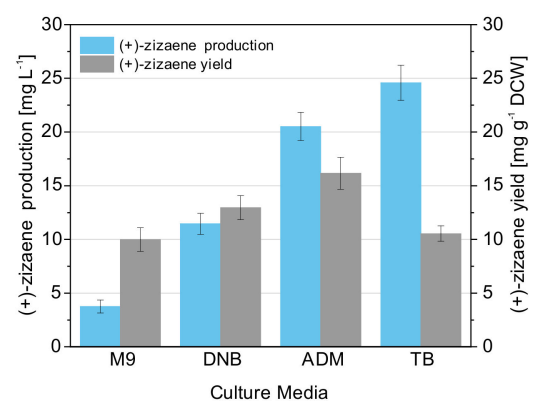

C

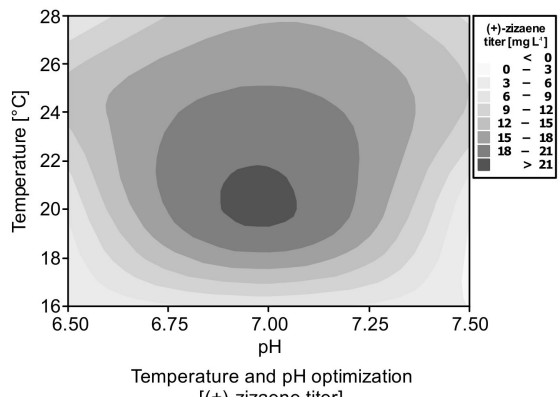

$\mathrm{E}$

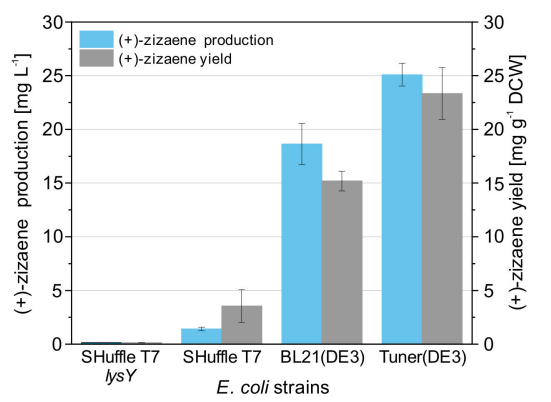

B

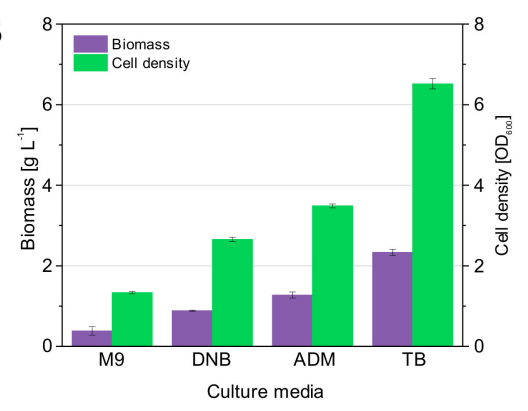

D

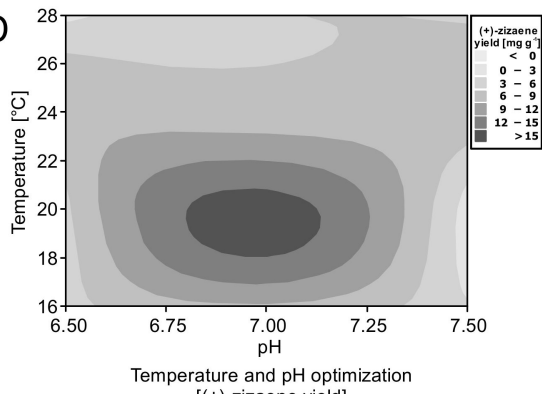

F

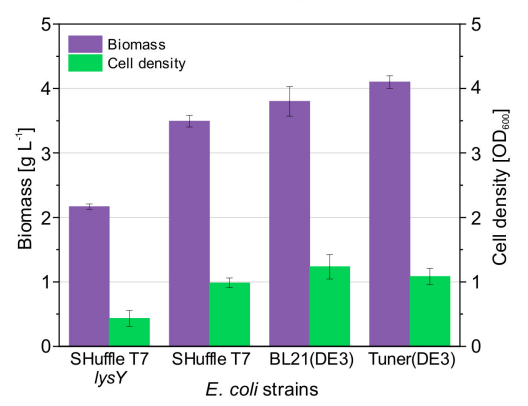

Figure 5. Optimization of the fermentation conditions and testing of E. coli strains for the improvement of the terpene performance. Evaluation of production media: (A) (+)-zizaene titers and yields, (B) biomass and cell density. Optimization of growth temperature and media $\mathrm{pH}$ : (C) (+)-zizaene titers, (D) (+)-zizaene yields. Evaluation of E. coli strains: (E) (+)-zizaene titers and yields, (F) biomass and cell density. Data are the mean of four independent replicates from production cultures after $24 \mathrm{~h}$ of induction, and the error bars represent the standard deviation. 
To further improve the fermentation conditions, factorial designs of two levels were implemented for the optimization of growth temperature and $\mathrm{pH}$ of the ADM medium. Accordingly, optimal (+)-zizaene levels were found between $19.5-21.8^{\circ} \mathrm{C}$ and $\mathrm{pH}$ 6.8-7.08 (Figure 5c) and for (+)-zizaene yields between $18-20.8^{\circ} \mathrm{C}$ and $\mathrm{pH}$ 6.8-7.1 (Figure 5d). Temperature affected (+)-zizaene levels differently than yields, whereas moderate (+)-zizaene levels $\left(15-21 \mathrm{mg} \mathrm{L}^{-1}\right)$ were shown at a broad range of temperature $\left(17.5-27.7^{\circ} \mathrm{C}\right)$. On the contrary, $\mathrm{pH}$ had nearly the same effect on both variables. Additionally, the highest levels of soluble $\mathrm{ZS}$ protein were found at lower $\mathrm{pH}$ and temperatures (Figure 6b). Tests at $\mathrm{pH} 6.5$ also produced the highest amounts of insoluble ZS protein, resulting in the lowest (+)-zizaene levels. Similarly, tests carried out at $16{ }^{\circ} \mathrm{C}$ dropped the $(+)$-zizaene levels despite the high amounts of soluble ZS protein, possibly due to enzymatic mechanisms. As a result, the optimal fermentation conditions were determined as $20^{\circ} \mathrm{C}$ and $\mathrm{pH} 7.0$, which improved the (+)-zizaene levels to $21.5 \mathrm{mg} \mathrm{L}^{-1}$ and yields to $16.2 \mathrm{mg} \mathrm{g}^{-1} \mathrm{DCW}$.

\section{A}
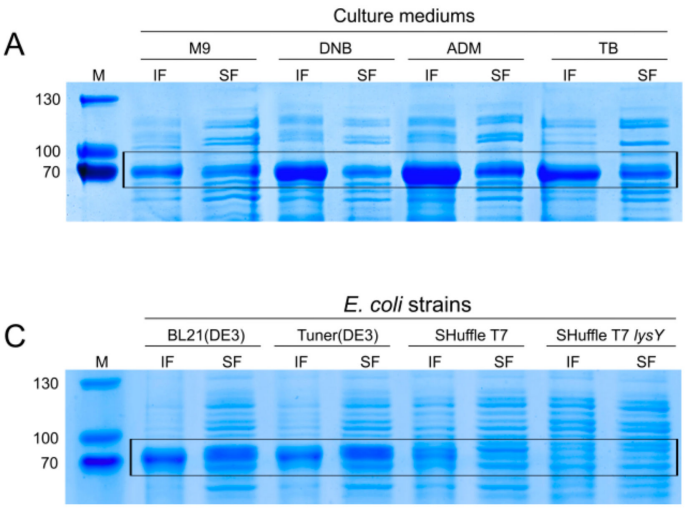

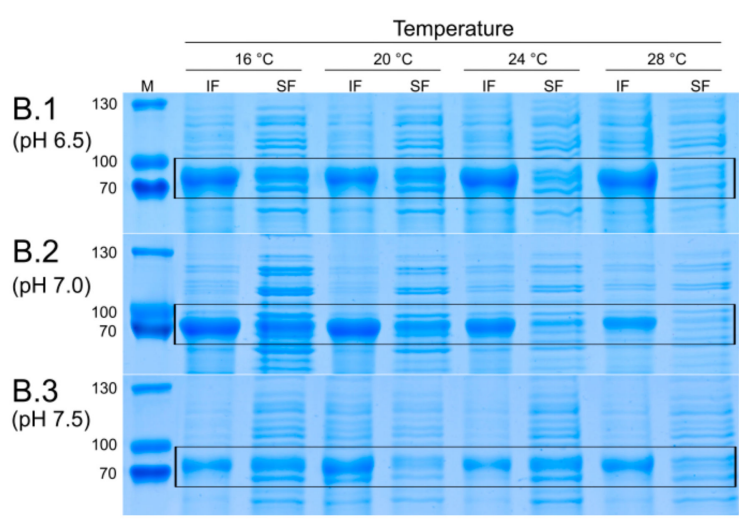

Figure 6. Analysis of the over-expression of soluble (SF) and insoluble (IF) ZS protein fractions from the optimization of fermentation conditions and testing of E. coli strains by $10 \%$ SDS-PAGE. (A) Culture media test. (B) Temperature and $\mathrm{pH}$ optimization. (C) E. coli strains test. (M) molecular marker.

Strain tests were carried out under optimal fermentation conditions (ADM medium, $20^{\circ} \mathrm{C}$ and $\mathrm{pH}$ 7) to assess the features of the E. coli B strains SHuffle T7, SHuffle T7 lysY, Tuner(DE3) and BL21(DE3), and measure their impact on the production of (+)-zizaene. The SHuffle-based strains were selected to test if there could be an enhancement in the folding of ZS due to the effect of a disulfide bond chaperone DsbC. Additionally, the SHuffle T7 lys Y variant reduces the basal expression for toxic genes through the expression of lysozyme, coded by the lys $Y$ gene. Similarly, the BL21(DE3) variant, the Tuner(DE3) strain lacks the lac $Y$ gene that codes for the $\beta$-galactosidase permease, which allows fine-tuning for induction and reduces basal expression. As a control, the BL21(DE3) strain was used. As presented in Figure 5e, the differences between the BL21-based and SHuffle-based strains were remarkable; unexpectedly, the best results were shown by the Tuner(DE3) strain, followed by the BL21(DE3), SHuffle T7, and SHuffle T7 lys Y strains. These observations demonstrate that the strains expressing the lowest number of recombinant proteins produced the highest cell growth (Figure 5f), and soluble ZS protein amounts (Figure 6c), and consequently, the highest (+)-zizaene titers and yields (shown by increasing number of recombinant proteins: Tuner(DE3): ZS; BL21(DE3): ZS, lacY; SHuffle T7: ZS, lacY, DsbC; SHuffle T7 lysY: ZS, lacY, DsbC, lysY). Overexpression of the chaperones by the SHuffle-based strains did not have the expected results; instead, it showed deleterious effects as observed from the low amounts of ZS protein. As a result, the strain that expressed the minimum number of recombinant proteins, the Tuner(DE3) strain, enhanced 1.2-fold the (+)-zizaene levels and 1.4-fold the yields in comparison with the control BL21(DE3) strain.

Finally, the applied approach for the optimization of the fermentation conditions improved the (+)-zizaene titers 2.2-fold and yields 1.7-fold when compared to the strains without optimization 
(Section 3.4), achieving the highest (+)-zizaene production of $25.09 \mathrm{mg} \mathrm{L}^{-1}$ and yield $23.33 \mathrm{mg} \mathrm{g}^{-1}$ DCW for this study.

\section{Discussion}

The production of (+)-zizaene was metabolically engineered in E. coli by a recombinant codon-optimized SUMO-fused ZS that enhanced the amounts of soluble ZS protein [10]. Moreover, the optimization of the metabolic flux to (+)-zizaene was the greatest challenge, where the FDP and ZS supply were identified as the limiting factors. Consequently, a strategy was applied to gradually increase the supply of both and augment the metabolic rate driving force towards (+)-zizaene.

Initially, production of $(+)$-zizaene was possible by using the endogenous MEP pathway from E. coli (TZS strain) but at a lower extent. The high amounts of soluble ZS protein and low titers of (+)-zizaene suggest a limitation on the FDP supply. For that reason, the exogenous MEV pathway was applied, which is the ubiquitous pathway in plants for the biosynthesis of the sesquiterpene substrate FDP [34]. Hence, the pMevZS vector was constructed as a polycistronic vector, including all the required genes for terpene production into one vector. Such a strategy has been used for the engineering of many terpenes $[23,28,35]$ because the maintenance of a single vector by the host cells is more efficient than for multi-vectors [36]. As a result, the overexpression of the MevZS strain did not increase the levels of (+)-zizaene as expected; possibly due to the lower amounts of soluble ZS protein than the TZS strain. This could be explained by the moderate strength of the lacUV5 promoter [37], theimproved variant of the lac promoter from E. coli [38]. Additionally, the ZS gene was placed eight genes downstream from the promoter in the polycistronic pMevZS vector and eventually, this gene order could affect the overexpression of ZS, as demonstrated by other studies [39-41]. Moreover, the overexpression of the nine genes produced a large mRNA transcript, which is usually more unstable as short transcripts [42]. Thus, the increase in the FDP supply and the decline in the soluble ZS protein amounts suggest that the limiting factor shifted to the ZS supply. This scenario was deleterious for an optimal metabolic rate, because ZS suffers substrate inhibition from FDP at higher levels of $5 \mu \mathrm{M}$, as shown in our previous report [20].

To raise the ZS supply, the monocistronic vectors pJbeiZS and pETZS were designed by cloning the ZS gene directly after the promoter and further co-transformed into the strain with the pMev vector. The use of the BZS+Mev strain was initially promising because it is capable of tuning the metabolic flux, using unique inducers for FDP (IPTG) and ZS (Arabinose). However, results with the $\mathrm{P}_{\mathrm{BAD}}$ promoter were similar to those obtained by the MevZS strain, possibly due to the similarity in the strength of the $\mathrm{P}_{\mathrm{BAD}}$ promoter versus the lacUV5 promoter [37]. Similar outcomes were demonstrated by others, where the lacUV5 and $\mathrm{P}_{\mathrm{BAD}}$ promoters produced low or even undetectable levels of sesquiterpenes [11,12]. Additionally, accumulation of toxic intermediates due to a higher metabolic burden could occur because the BZS+Mev strain harbors the high-copy pJbeiZS plasmid with the pBBR1 origin of replication [43]. On the other hand, overexpression of soluble ZS protein with the T7-promoter (TZS+Mev strain) was drastically higher than with the $\mathrm{P}_{\mathrm{BAD}}$ promoter (BZS+Mev strain) and subsequently, the production of (+)-zizaene increased considerably.

We ventured to raise further the ZS supply by adding a second copy of the ZS gene through the TZS+MevZS strain. As a result, the production of (+)-zizaene was the greatest of all the engineered strains and suggests that the limiting factor was still the ZS supply. The improvement in (+)-zizaene levels could be due to the effect of overexpressing the $Z S$ genes by two different promoters on two different vectors (T7 in pETZS and lacUV5 in pMevZS). Such strategy could have been a contributive factor, possibly by overexpressing the ZS gene by different promoters, by RBS strength differences from the used vectors, and by the vector copy numbers, which are unequal on multi-plasmid strains due to differences between replication origins, antibiotic markers, and plasmid sizes $[16,42]$. However, more tests are required to draw such conclusions. Additionally, it seems that the in vivo production of (+)-zizaene requires higher amounts of the TPS when compared to other sesquiterpenes such as vetispiradiene ( $\mathrm{K}_{\mathrm{M}}=0.7 \mu \mathrm{M}$ for the vetispiradiene synthase) [44], due to the low enzyme activity 
of $\mathrm{ZS}\left(\mathrm{K}_{\mathrm{M}}=0.88 \mu \mathrm{M}\right)$ [20]. Therefore, increasing the copy number of the TPS gene in a multi-vector strain was a plausible strategy to improve the flux to (+)-zizaene.

Optimal fermentation conditions are crucial for efficient microbial growth and metabolization of glucose flux towards terpenes, as demonstrated by many reports $[11,45,46]$. Regarding the media evaluation, the ADM medium achieved the highest production of (+)-zizaene when compared to the other defined media tests. The main difference in media formulation between tests was the higher amount of nitrogen from the ADM medium, suggesting that nitrogen concentration was the most relevant factor; particularly, because nitrogen is required for the biosynthesis of amino acids that regulates the production of cellular and recombinant proteins [47]. This could explain the higher cell growth and soluble ZS protein levels from the ADM medium tests when compared to the other tests, which in turn improved the (+)-zizaene levels.

Optimization of the temperature and media $\mathrm{pH}$ can enhance the production of sesquiterpene as observed with the microbial production of vetispiradiene, 5-epi-aristolechene and $(+)-\delta$-cadinene [11]. For the production of (+)-zizaene, the optimal fermentation conditions were found at $20{ }^{\circ} \mathrm{C}$ and $\mathrm{pH}$ 7.0, which differ from the optimal reaction conditions from the ZS in in vitro biotransformations with FDP $\left(36^{\circ} \mathrm{C}, \mathrm{pH}\right.$ 7.5) [20]. Thus, the greatest difference between the experimental conditions was the temperature, due to its relevant effect over protein synthesis rate, cell growth, and enzyme activity [11,48]. Accordingly, tests cultivated at $16^{\circ} \mathrm{C}$ and $\mathrm{pH}$ 6.5-7, overexpressed high amounts of soluble ZS protein but the (+)-zizaene levels and cell growth were low. These results suggest that the activity of the ZS was drastically reduced at $16^{\circ} \mathrm{C}$, due to its preference for higher temperatures (optimal at $36^{\circ} \mathrm{C}$ ). On the other hand, temperatures higher than $20^{\circ} \mathrm{C}$ resulted in higher amounts of insoluble ZS protein than the soluble form. These observations confirm that an optimal temperature of $20^{\circ} \mathrm{C}$ was required to achieve a balance between cell growth and active $\mathrm{ZS}$ protein. Regarding the effect of the media $\mathrm{pH}$ on (+)-zizaene production, the optimal $\mathrm{pH}$ was found to be neutral $\mathrm{pH}$ and values different than that lowered the (+)-zizaene titers. Additionally, lower $\mathrm{pH}$ values promoted the formation of insoluble ZS protein. Such behavior was observed before in uncontrolled-pH E. coli cultures grown in shake flasks, whereas overexpression of fused SpA- $\beta$ gal protein at $\mathrm{pH}<5.5$ augmented the inclusion body formation, possibly due to regulatory mechanisms for $\mathrm{pH}$ homeostasis [49]. Therefore, tests grown at $\mathrm{pH} 7$ at $20^{\circ} \mathrm{C}$ achieved the balance between insoluble and soluble ZS protein fractions that led to the highest production of (+)-zizaene.

The evaluation of E. coli B strains revealed considerable differences in terpene production due to the particular feature of each strain. The terpene performance increased with the strains that expressed the lower number of recombinant proteins such as the BL21(DE3)-based strains. These results suggest that the expression of the ZS protein is not affected by basal expression (lys $Y$ gene), neither the $\beta$-galactoside permease is required (lacY gene), nor the chaperon DsbC enhanced the protein folding and disulfide bond formation, although the ZS protein contains cysteines. On the contrary, overexpression of DsbC drastically dropped the amounts of soluble ZS protein and the (+)-zizaene titers. Consequently, the Tuner(DE3) strain achieved the best performance for terpene production by overexpressing the minimum number of recombinant proteins, thus avoiding the production of unnecessary proteins ( $\beta$-galactoside permease, $\mathrm{DsbC}$, and lysozyme). This strategy diminished the metabolic burden, defined as the resources consumed for cell maintenance and recombinant protein synthesis that is inversely proportional to cell growth [48]. This was confirmed by the higher biomass amount from the Tuner(DE3) strain when compared to the other tested strains. As a result, the lower metabolic burden from the Tuner(DE3) strain improved the efficiency of the carbon flux towards (+)-zizaene.

\section{Conclusions}

In this work, we demonstrated the metabolic engineering of $E$. coli strains for the in vivo production of (+)-zizaene. Moreover, we optimized the limiting factors of the metabolic flux to (+)-zizaene by the overexpression of the MEV pathway, and by boosting the ZS supply by increasing the number of copies 
of the ZS gene with T7 promoters on a multi-plasmid strain. Final improvement was achieved by optimizing the fermentation conditions and testing of E. coli B strains to a final (+)-zizaene production of $25.09 \mathrm{mg} \mathrm{L}^{-1}$ at the shake flask scale. This work offers new insights into the optimization of the metabolic pathway and fermentation conditions for the in vivo production of sesquiterpenes and the development of a novel microbial platform towards the industrialization of fragrant molecules.

Supplementary Materials: The following are available online at http://www.mdpi.com/2073-4425/10/6/478/s1, Figure S1: Confirmation of seamless cloning for pMevZS; Figure S2: Confirmation of seamless cloning for pJbeiZS; Table S1: Mass spectra of the identified products.

Author Contributions: Funding acquisition and conceptualization-T.S. and S.B.; Methodology-S.B. and F.A.; Experimentation, data analysis, and manuscript draft preparation-F.A.; Manuscript revision-S.B. All authors agreed to the final version.

Funding: This research was funded by the PINN program from the Ministry of Science, Technology and Telecommunications of Costa Rica (MICITT), grant PED-058-2015-1 and by the Open Access Fund of the Leibniz Universität Hannover.

Acknowledgments: We are grateful for the assistance provided for the product identification by Daniel Sandner and Ulrich Krings from the Institute of Food Chemistry at the Leibniz University of Hannover. We thank Lukas Koch for the technical support for the cultivations.

Conflicts of Interest: The authors declare no conflict of interest. The funders had no role in the design of the study; in the collection, analyses, or interpretation of data; in the writing of the manuscript, or in the decision to publish the results.

\section{References}

1. Carvalho, I.T.; Estevinho, B.N.; Santos, L. Application of microencapsulated essential oils in cosmetic and personal healthcare products-A review. Int. J. Cosmet. Sci. 2016, 38, 109-119. [CrossRef] [PubMed]

2. Hüsnü, K.; Başer, C.; Demirci, F. Chemistry of essential oils. In Flavours and Fragrances; Berger, R.G., Ed.; Springer-Verlag: Berlin, Germany, 2007; pp. 43-86.

3. Belhassen, E.; Filippi, J.J.; Brévard, H.; Joulain, D.; Baldovini, N. Volatile constituents of vetiver: A review. Flavour Fragr. J. 2015, 30, 26-82. [CrossRef]

4. Gnansounou, E.; Alves, C.M.; Raman, J.K. Multiple applications of vetiver grass-A review. Int. J. Environ. Sci. 2017, 2, 125-141.

5. Sanganeria, P. Essential Oils Market Report Summer 2018; Report summer 2018; Ultra International B.V: Spijkenisse, The Netherlands, 2018; pp. 36-39.

6. Vetiver oil market expected to reach $\$ 169$ Million By 2022. Available online: https://www.grandviewresearch. com/press-release/global-vetiver-oil-market (accessed on 22 April 2019).

7. Talansier, E.; Braga, M.E.M.; Rosa, P.T.V.; Paolucci-Jeanjean, D.; Meireles, M.A.A. Supercritical fluid extraction of vetiver roots: A study of SFE kinetics. J. Supercrit. Fluids 2008, 47, 200-208. [CrossRef]

8. Akhila, A.; Rani, M. Chemical constituents and essential oil biogenesis in Vetiveria zizanioides. In Vetiveria: The Genus Vetiveria; Maffei, M., Ed.; Taylor \& Francis: London, UK, 2002; pp. 80-117. ISBN 0-415-27586-5.

9. Tholl, D. Terpene synthases and the regulation, diversity and biological roles of terpene metabolism. Curr. Opin. Plant Biol. 2006, 9, 297-304. [CrossRef] [PubMed]

10. Hartwig, S.; Frister, T.; Alemdar, S.; Li, Z.; Scheper, T.; Beutel, S. SUMO-fusion, purification, and characterization of a (+)-zizaene synthase from Chrysopogon zizanioides. Biochem. Biophys. Res. Commun. 2015, 458, 883-889. [CrossRef]

11. Martin, V.J.J.; Yoshikuni, Y.; Keasling, J.D. The in vivo synthesis of plant sesquiterpenes by Escherichia coli. Biotechnol. Bioeng. 2001, 75, 497-503. [CrossRef]

12. Nybo, S.E.; Saunder, J.; McCormick, S. Metabolic engineering of Escherichia coli for production of valerenadiene. J. Biotechnol. 2017, 262, 60-66. [CrossRef]

13. Guan, Z.; Breazeale, S.D.; Raetz, C.R.H. Extraction and identification by mass spectrometry of undecaprenyl diphosphate-MurNAc-pentapeptide-GlcNAc from Escherichia coli. Anal. Biochem. 2005, 345, 336-339. [CrossRef]

14. Okada, K.; Minehira, M.; Zhu, X.; Suzuki, K.; Nakagawa, T.; Matsuda, H.; Kawamukai, M. The ispB gene encoding octaprenyl diphosphate synthase is essential for growth of Escherichia coli. J. Bacteriol. 1997, 179, 3058-3060. [CrossRef] 
15. Kim, S.; Keasling, J.D. Nonmevalonate isopentenyl diphosphate synthesis pathway in Escherichia coli enhances lycopene production. Biotechnol. Bioeng. 2001, 72, 408-415. [CrossRef]

16. Sørensen, H.P.; Mortensen, K.K. Advanced genetic strategies for recombinant protein expression in Escherichia coli. J. Biotechnol. 2005, 115, 113-128. [CrossRef] [PubMed]

17. Martin, V.; Pitera, D.; Withers, S.; Newman, J.; Keasling, J. Engineering a mevalonate pathway in Escherichia coli for production of terpenoids. Nat. Biotechnol. 2003, 21, 796-802. [CrossRef] [PubMed]

18. Peralta-Yahya, P.P.; Ouellet, M.; Chan, R.; Mukhopadhyay, A.; Keasling, J.D.; Lee, T.S. Identification and microbial production of a terpene-based advanced biofuel. Nat. Commun. 2011, 2, 483-488. [CrossRef] [PubMed]

19. Christianson, D.W. Structural biology and chemistry of the terpenoid cyclases. Chem. Rev. 2006, 106, 3412-3442. [CrossRef] [PubMed]

20. Aguilar, F.; Hartwig, S.; Scheper, T.; Beutel, S. Catalytical specificity, reaction mechanisms, and conformational changes during catalysis of the recombinant SUMO (+)-zizaene synthase from Chrysopogon zizanioides. ACS Omega 2019, 4, 6199-6209. [CrossRef]

21. Green, M.R.; Sambrook, J. Molecular Cloning: A Laboratory Manual, 4th ed.; Cold Spring Harbor Laboratory Press: New York, NY, USA, 2012; ISBN 978-1-936113-42-2.

22. Guzman, L.M.; Belin, D.; Carson, M.J.; Beckwith, J. Tight regulation, modulation, and high-level expression by vectors containing the arabinose PBAD promoter. J. Bacteriol. 1995, 177, 4121-4130. [CrossRef]

23. Alonso-Gutierrez, J.; Chan, R.; Batt, T.S.; Adams, P.D.; Keasling, J.D.; Petzold, C.J.; Lee, T.S.; Adams, P.D. Metabolic engineering of Escherichia coli for limonene and perillyl alcohol production. Metab. Eng. 2013, 19, 33-41. [CrossRef]

24. Li, Z.; Carstensen, B.; Rinas, U. Smart sustainable bottle (SSB) system for E. coli based recombinant protein production. Microb. Cell Fact. 2014, 13, 2-9. [CrossRef]

25. Song, J.M.; Wei, D.Z. Production and characterization of cellulases and xylanases of Cellulosimicrobium cellulans grown in pretreated and extracted bagasse and minimal nutrient medium M9. Biomass Bioenergy 2010, 34, 1930-1934. [CrossRef]

26. Rodríguez-Aparicio, L.B.; Reglero, A.; Ortiz, A.I.; Luengo, J.M. Effect of physical and chemical conditions on the production of colominic acid by E. coli in defined medium. Appl. Microbiol. Biotechnol. 1988, 27, 474-483. [CrossRef]

27. Van Del Dool, H.; Kratz, P. A generalization of the retention index system including linear temperature programmed gas-liquid partition chromatography. J. Chromatogr. A 1963, 11, 463-471. [CrossRef]

28. Wang, C.; Yoon, S.H.; Jang, H.J.; Chung, Y.R.; Kim, J.Y.; Choi, E.S.; Kim, S.W. Metabolic engineering of Escherichia coli for $\alpha$-farnesene production. Metab. Eng. 2011, 13, 648-655. [CrossRef] [PubMed]

29. Hartwig, S.; Frister, T.; Alemdar, S.; Li, Z.; Krings, U.; Berger, R.G.; Scheper, T.; Beutel, S. Expression, purification and activity assay of a patchoulol synthase cDNA variant fused to thioredoxin in Escherichia coli. Protein Expr. Purif. 2014, 97, 61-71. [CrossRef]

30. Alemdar, S.; Hartwig, S.; Frister, T.; König, J.C.; Scheper, T.; Beutel, S. Heterologous expression, purification, and biochemical characterization of $\alpha$-humulene synthase from Zingiber zerumbet Smith. Appl. Biochem. Biotechnol. 2016, 178, 474-489. [CrossRef] [PubMed]

31. Newman, J.D.; Marshall, J.; Chang, M.; Nowroozi, F.; Paradise, E.; Pitera, D.; Newman, K.L.; Keasling, J.D. High-level production of amorpha-4,11-diene in a two-phase partitioning bioreactor of metabolically engineered Escherichia coli. Biotechnol. Bioeng. 2006, 95, 684-691. [CrossRef]

32. Wang, C.; Yoon, S.H.; Shah, A.A.; Chung, Y.R.; Kim, J.Y.; Choi, E.S.; Keasling, J.D.; Kim, S.W. Farnesol production from Escherichia coli by harnessing the exogenous mevalonate pathway. Biotechnol. Bioeng. 2010, 107, 421-429. [CrossRef]

33. Korz, D.; Rinas, U.; Hellmuth, K.; Sanders, E.; Deckwer, W. Simple fed-batch technique for high cell density cultivation of Escherichia coli. J. Biotechnol. 1995, 39, 59-65. [CrossRef]

34. Tholl, D. Biosynthesis and biological functions of terpenoids in plants. In Advances in Biochemical Engineering/Biotechnology; Schrader, J., Bohlmann, J., Eds.; Springer International: Basel, Switzerland, 2015; pp. 63-106.

35. Cao, Y.; Zhang, R.; Liu, W.; Zhao, G.; Niu, W.; Guo, J.; Xian, M.; Liu, H. Manipulation of the precursor supply for high-level production of longifolene by metabolically engineered Escherichia coli. Sci. Rep. 2019, 9, 1-10. [CrossRef] 
36. Kumar, S.; Jain, K.K.; Bhardwaj, K.N.; Chakraborty, S.; Kuhad, R.C. Multiple genes in a single host: Cost-effective production of bacterial laccase $(\cot \mathrm{A})$, pectate lyase (pel), and endoxylanase (xyl) by simultaneous expression and cloning in single vector in E. coli. PLoS ONE 2015, 10, 1-15. [CrossRef]

37. Samuelson, J. Bacterial Systems. In Production of Membrane Proteins: Strategies for Expression and Isolation; Robinson, A.S., Ed.; Wiley-VCH Verlag GmbH \& Co: Weinheim, Germany, 2011; pp. 11-35. ISBN 9780470871942.

38. Tegel, H.; Ottosson, J.; Hober, S. Enhancing the protein production levels in Escherichia coli with a strong promoter. FEBS J. 2011, 278, 729-739. [CrossRef] [PubMed]

39. Lv, X.; Xu, H.; Yu, H. Significantly enhanced production of isoprene by ordered coexpression of genes $d x s$, dxr, and idi in Escherichia coli. Appl. Microbiol. Biotechnol. 2013, 97, 2357-2365. [CrossRef] [PubMed]

40. Du, F.L.; Yu, H.L.; Xu, J.H.; Li, C.X. Enhanced limonene production by optimizing the expression of limonene biosynthesis and MEP pathway genes in E. coli. Bioresour. Bioprocess. 2014, 1, 1-10. [CrossRef]

41. Tan, S. A modular polycistronic expression system for overexpressing protein complexes in Escherichia coli. Protein Expr. Purif. 2001, 21, 224-234. [CrossRef] [PubMed]

42. Perrakis, A.; Romier, C. Assembly of protein complexes by coexpression in prokaryotic and eukaryotic hosts: An overview. In Structural Proteomics High-Throughput Methods; Kobe, B., Guss, M., Huber, T., Eds.; Humana Press: New York, NY, USA, 2008; ISBN 9781588298096.

43. Jones, K.L.; Kim, S.W.; Keasling, J.D. Low-copy plasmids can perform as well as or better than high-copy plasmids for metabolic engineering of bacteria. Metab. Eng. 2000, 2, 328-338. [CrossRef]

44. Mathis, J.R.; Back, K.; Starks, C.; Noel, J.; Poulter, C.D.; Chappel, J. Pre-steady-state study of recombinant sesquiterpene cyclases. Biochemistry 1997, 36, 8340-8348. [CrossRef]

45. Wu, W.; Liu, F.; Davis, R.W. Engineering Escherichia coli for the production of terpene mixture enriched in caryophyllene and caryophyllene alcohol as potential aviation fuel compounds. Metab. Eng. Commun. 2018, 6, 13-21. [CrossRef]

46. Huang, X.; Xiao, Y.; Köllner, T.G.; Zhang, W.; Wu, J.; Wu, J.; Guo, Y.; Zhang, Y. Identification and characterization of (E)- $\beta$-caryophyllene synthase and $\alpha / \beta$-pinene synthase potentially involved in constitutive and herbivore-induced terpene formation in cotton. Plant Physiol. Biochem. 2013, 73, 302-308. [CrossRef]

47. Chubukov, V.; Desmarais, J.J.; Wang, G.; Chan, L.J.G.; Baidoo, E.E.K.; Petzold, C.J.; Keasling, J.D.; Mukhopadhyay, A. Engineering glucose metabolism of Escherichia coli under nitrogen starvation. npj Syst. Biol. Appl. 2017, 3, 1-7. [CrossRef]

48. Sørensen, H.P.; Mortensen, K.K. Soluble expression of recombinant proteins in the cytoplasm of Escherichia coli. Microb. Cell Fact. 2005, 8, 1-8. [CrossRef]

49. Strandberg, L.; Enfors, S.O. Factors influencing inclusion body formation in the production of a fused protein in Escherichia coli. Appl. Environ. Microbiol. 1991, 57, 1669-1674. [PubMed] 